\title{
Is Obstructive Sleep Apnea more Prevalent than Central Sleep Apnea in Patients with Systolic Heart Failure? A Retrospective Study
}

Hasan $A^{1^{*}}$, Uzma $\mathbf{N}^{2}$, Abdullah $\mathrm{F}^{1}$, Hannan $\mathrm{HA}^{2}$, Narasimhan $\mathrm{C}^{3}$ and Rao $\mathrm{L}^{4}$

${ }^{1}$ Department of Respiratory Medicine, Deccan College of Medical Sciences, Hyderabad, India

${ }^{2}$ Department of Physiology, Deccan College of Medical Sciences, Hyderabad, India

${ }^{3}$ Department of Cardiology, Care Hospital, Hyderabad, India

${ }^{4}$ Department of Cardiology, Deccan College of Medical Sciences, Hyderabad, India

*Corresponding author: Hasan A, Department of Respiratory Medicine, Deccan College of Medical Sciences, Hyderabad, India, Tel: +91-40-24340547; Fax: +91-40-24340235; E-mail: ashfaqhasanmd@gmail.com

Received date: April 17, 2017; Accepted date: April 28, 2017; Published date: May 6, 2017

Copyright: (C) 2017 Hasan A, et al. This is an open-access article distributed under the terms of the Creative Commons Attribution License, which permits unrestricted use, distribution, and reproduction in any medium, provided the original author and source are credited.

\begin{abstract}
Central sleep apnea (CSA) rather than obstructive sleep apnea (OSA) is widely believed to be the dominant form of sleep apnea (SA) in patients with heart failure (HF). Hitherto, no study has characterized sleep disordered breathing (SDB) in Indian subjects with heart failure and evaluated its impact on severity of HF, which this study attempts to do. A retrospective data-analysis was done in 65 consecutive patients with stable mild-to-moderate $\mathrm{HF}$ referred for evaluation on the basis of fatigue and excessive daytime somnolence (EDS) regarded by the institute's cardiologists. Patients with ejection fraction (EF) $<55 \%$ or LV fractional shortening of $28 \%$ were included in the study. PSG was scored according to current AASM recommendations. Based on the Apnea-Hypopnea Index (AHI), OSA was classified as mild (AHI:5-15), moderate (AHI: 15-30) and severe (AHI: $>30$ ). HF was arbitrarily classified as mild $(E F:<35 \%)$ moderate (EF:35-45\%) and severe (EF:45-55\%). OSA emerged as the exclusive form of SA $(95.4 \%$; $\mathrm{n}=65$ ) and was more severe in males. Patients with more severe HF tended to be less obese, and interestingly to have less severe OSA. In contrast to Western literature, OSA seems to be by far the most prevalent form of sleep apnea in Indian subjects with HF. HF mortality is known to be high in underweight individuals yet, persons with severe $\mathrm{HF}$ are often less obese and partly by reason of a lower BMI, appear to be relatively protected against severe OSA and severe nocturnal hypoxemia. This study thus raises important and intriguing questions which merit further enquiry.
\end{abstract}

Keywords: Heart failure; Obstructive sleep apnea; Central sleep apnea; Body mass index; Apnea-hypopnea index (AHI)

\section{Introduction}

Heart Failure (HF) is now considered to be an epidemic. The burden of HF may be underestimated, since population-based studies suggest that a substantial portion of those with systolic dysfunction are asymptomatic [1]. Importantly, even in the absence of symptoms impaired ventricular function is associated with an increased mortality risk and this is an often under-recognized fact [2].

However, the mechanisms of heart failure as broadly understood are primarily based on the information acquired during the wakefulness state: a better understanding of the nocturnal events impacting upon heart failure is required.

Patients with HF sleep fewer hours and suffer from interrupted sleep and intermittent hypoxia which is a hallmark feature of sleep apnea $[3,4]$.

Sleep apnea is part of the spectrum of disorders characterized by abnormal breathing during sleep, which range from intermittent to persistent snoring, upper airway resistance syndrome and obesity hypoventilation syndrome (OHVS) [5].

Sleep Apnea is classified into Obstructive Sleep Apnea (OSA/OSAS), Central Sleep Apnea (CSA) or Mixed Sleep Apnea [6]. Obstructive apneas and hypopneas result from complete or partial collapse of a narrowed pharynx, respectively, whereas central apneas and hypopneas arise from reductions in central respiratory drive.

Sleep apnea and heart failure share a bidirectional relationship, each worsening the outcome of the other. At least $50 \%$ of patients with HF have OSA or CSA, both of which are capable of disrupting the normal restorative effects of sleep on the cardiovascular system [7].

OSA is far more common in the general population than is CSA. It is also an important denominator in cardiac disease. Emerging data suggest that cardiac function influences upper airway patency in OSA by myriad intermediary mechanisms such as ventilatory drive changes, alterations in circulation time, peri-pharyngeal edema and neurohumoral control [8].

On the other hand sleep apnea (both obstructive and central) can potentially exacerbate heart failure by exposing the heart to intermittent hypoxia, sympathetic activation and vascular endothelial dysfunction, increased preload and afterload.

Given the prevalence and public health burden of both sleepdisordered breathing and HF, the implications for effective treatment of these often comorbid conditions are enormous [9].

Therefore, the purpose of this study is twofold: to determine the prevalence of dominant type of sleep apnea in patients with HF referred to our sleep laboratory; and to determine the impact of severity of HF with severity of sleep apnea. 


\section{Materials and Methods}

\section{Study protocol}

76 consecutive patients with congestive heart failure referred to the Department of Pulmonary Medicine of this institute for suspected sleep disordered breathing (SDB) by cardiologists we're taken up for the study. 6 patients declined participation; 5 patients did not participate as there were already on therapy for OSA. 65 patients were enrolled in the study and underwent polysomnography.

Data on demographic characteristics, medical history, medication use and other habits were obtained with the use of a standardized questionnaire before the initiation of overnight polysomnography. Each patient's height and weight were recorded, and the body-mass index (BMI) calculated.

Sleep-history data which included a validated measure of daytime sleepiness (the Epworth Sleepiness Scale), fatigue score and selfreported habitual snoring (defined as loud snoring occurring "frequently" or "constantly") were obtained. Most interviews were attended by the patient's spouse or a close relative staying at home.

Clinical data included any history of hypertension, atrial fibrillation (or other arrhythmias), diabetes mellitus or hyperlipidemia-either reported by the patient on the baseline medical questionnaire, or noted by the referred physician.

The Study was approved by the Institutional Ethics Committee, Deccan College of Medical Sciences, Hyderabad and informed consent was taken from all the participants.

\section{Inclusion criteria and exclusion criteria}

Patients with an ejection fraction (EF) that was below normal limits $(<55 \%)$ who were considered clinically stable for out-patient evaluation and treatment were included in the study.

Patients with unstable angina, acute pulmonary oedema congenital and valvular heart disease, and those patients with heart failure who were considered too sick to undergo evaluation were excluded from the study.

\section{Cardiac assessment}

Left ventricular ejection fraction (LVEF) recorded within 6 months of the diagnostic sleep study was used as an objective measure of cardiac function. The LVEF was determined at rest during the daytime while patients were awake, using 2-D echocardiography.

The quantitation and reporting of LVEF were performed by personnel who were not aware of the patients sleep study findings.

Systolic heart failure was defined by:

- Left ventricular ejection fraction (LVEF) of 55\%, which was measured by either nuclear angiography or an echocardiography

- Left ventricular fractional shortening of $28 \%$ as measured by echocardiography [10]. HF was arbitrarily classified as mild (EF: $<35 \%)$ moderate (EF:35-45\%) and severe (EF:45-55\%).

\section{Assessment of obstructive sleep apnea}

A standard full-night diagnostic PSG was performed in each subject. Bedtime was left to each subject's individual choice, and at least 7 hours recording time was obtained. Data were collected from an electroencephalogram, a bilateral electro-oculogram, a submental electromyogram, and an electrocardiogram.

Data analyses were collected using a 16-channel computerized sleep system. Total sleep time was defined as the time from the first to last recorded sleep period, excluding wakefulness.

OSA were classified according to apnea-hypopnea index (AHI) values: AHI <5: normal, AHI 5-15: mild, AHI 15-30: moderate, AHI $>30$ : severe [11]. Based on WHO classification of BMI $\left(\mathrm{kg} / \mathrm{m}^{2}\right)$, patients were divided into 4 categories: normal (BMI range 18.50-24.99), overweight (BMI 25-29.99), obese (BMI 30-39.99), and morbid obese (BMI $\geq 40)$ [12].

\section{Statistical analysis}

Student's t-test was used to compare mean values at baseline among the OSA group with those in the control group. Categorical data were compared with the use of the 2 paired $t$ test. Pearson's coefficient was used to evaluate the association between normally distributed continuous variables; Spearman rank correlation test was used to evaluate the association between nonparametric variables. Data were expressed as mean \pm SD. Significance was defined as $p$ value of $<0.05$. All statistical tests were performed with the uses of SPSS version-18 and ORIGIN Pro8.0 software's.

\section{Results}

A total of 77 consecutive patients were referred to the sleep center during this study period, of whom, 65 patients were eligible to participate in the sleep study, 11 patients were deemed ineligible for various reasons. Table 1 shows the demographic and other relevant data of study population. OSA was found to be the most dominant form of SDB in $95.4 \%$ patients and $4.6 \%$ were found to have CSA; none of the patients, however, were found to have mixed SA. The mean \pm SD of AHI was $31.5 \pm 17.6$ and the distribution of patients that were classified as mild, moderate and severe OSA (with respect to the AHI criteria discussed above), was $23 \%, 35.4 \%$, and $27 \%$, respectively. Based on WHO classification of BMI $\left(\mathrm{kg} / \mathrm{m}^{2}\right), 21.5 \%$ of patients had BMI within normal range (18.50-24.99), 27.7\% were overweight (BMI 25-29.99), 46.2\% were in obese category (BMI 30-39.99), and $4.6 \%$ were morbidly obese $(\mathrm{BMI} \geq 40)$. $2.3 \%$ of patients in the study group were found to have mild heart failure (EF: $<35 \%), 60 \%$ moderate (EF: $35-45 \%)$ and $27.7 \%$ severe (EF:45-55\%) heart failure respectively. Gender specific demographic data is illustrated in Table 2. The OSA was more severe in males. The mean \pm SD age in males was $55.2 \pm 7.7$ and $59.4 \pm 8.4$ years in females respectively. BMI was found to be 31.09 \pm 6.82 in males whereas in females it was $28.88 \pm 5.7$.

Through the correlation between AHI and BMI among the study population after controlling for gender and heart failure was statistically not significant $(\mathrm{r}=0.223, \mathrm{p}=0.08)$, a step-ladder incremental trend was noticed in median AHI among BMI's (Normal $\cong 15$, overweight/obese $=30$ and morbidly obese 3) (Figure 1). The comparative analysis of severity of heart failure in association with AHI and HF category is shown in Figure 2. There was highly significant association found between BMI category and Heart failure category $\left(\chi^{2}(\mathrm{df}=3)=22.938, \mathrm{p}=0.000\right)$. Those study subjects (in contrast to overweight and obese category) who had a normal BMI were incidentally found to be having high $\mathrm{AHI}$ and the most severe heart failure among the subjects studied (Figure 2). 
Citation: Hasan A, Uzma N, Abdullah F, Hannan HA, Narasimhan C, et al. (2017) Is Obstructive Sleep Apnea more Prevalent than Central Sleep Apnea in Patients with Systolic Heart Failure? A Retrospective Study. J Clin Respir Dis Care 3: 126. doi:10.4172/2472-1247.1000126

Page 3 of 7

\begin{tabular}{|c|c|c|c|}
\hline \multicolumn{2}{|l|}{ Parameters } & Mean \pm SD & Number (\%) \\
\hline \multicolumn{2}{|l|}{ Age (years) } & $56 \pm 8$ & \\
\hline \multicolumn{4}{|l|}{ Body Mass Index $\left(\mathrm{kg} / \mathrm{m}^{2}\right)$} \\
\hline \multirow[t]{4}{*}{ BMI Category } & Normal & \multirow[t]{7}{*}{$30.51 \pm 6.58$} & $14(21.5 \%)$ \\
\hline & Overweight & & $18(27.7 \%)$ \\
\hline & Obese & & $30(46.2 \%)$ \\
\hline & Morbid obesity & & $3(4.6 \%)$ \\
\hline \multirow[t]{3}{*}{ Heart failure category } & Mild & & $8(12.3 \%)$ \\
\hline & Moderate & & $39(60 \%)$ \\
\hline & Severe & & $18(27.7 \%)$ \\
\hline \multicolumn{4}{|c|}{ Apnea Hypopnea Index (Events/hour) } \\
\hline \multirow[t]{3}{*}{ AHI Category (Events/hour) } & Mild & \multirow[t]{6}{*}{$31.5 \pm 17.6$} & $15(23 \%)$ \\
\hline & Moderate & & $23(35.4 \%)$ \\
\hline & Severe & & $27(41.5 \%)$ \\
\hline \multirow[t]{3}{*}{ Sleep-disordered breathing } & Mixed sleep apnea & & 0 \\
\hline & Central sleep apnea & & $3(4.6 \%)$ \\
\hline & Obstructive sleep apnea & & $62(95.4 \%)$ \\
\hline & & \multicolumn{2}{|l|}{ Mean \pm SD } \\
\hline \multicolumn{2}{|l|}{ Sleep Efficiency (\%) } & \multicolumn{2}{|l|}{$75.3 \pm 13.1$} \\
\hline \multicolumn{2}{|l|}{ Apneas (Events/hour) } & \multicolumn{2}{|l|}{$43 \pm 35$} \\
\hline \multicolumn{2}{|l|}{ Hypopneas (Events/hour) } & \multicolumn{2}{|l|}{$106 \pm 66$} \\
\hline \multicolumn{2}{|l|}{ Apnea REM (Events/night) } & \multicolumn{2}{|l|}{$1 \pm 4$} \\
\hline \multicolumn{2}{|l|}{ Apnea NREM (Events/night) } & \multicolumn{2}{|l|}{$11 \pm 12$} \\
\hline \multicolumn{2}{|l|}{ Hyponea REM (Events/night) } & \multicolumn{2}{|l|}{$5 \pm 8$} \\
\hline \multicolumn{2}{|l|}{ Hyponea NREM (Events/night) } & \multicolumn{2}{|l|}{$101 \pm 68$} \\
\hline \multicolumn{2}{|l|}{ Wake-after-sleep Onset (min) } & \multicolumn{2}{|l|}{$85.8 \pm 49.4$} \\
\hline \multicolumn{2}{|l|}{ Lowest $\mathrm{O}_{2}$ saturation (\%) } & \multicolumn{2}{|l|}{$79 \pm 10$} \\
\hline
\end{tabular}

Table 1: Demographic characteristics of participants.

\begin{tabular}{|c|c|c|c|c|c|}
\hline \multirow{2}{*}{\multicolumn{2}{|c|}{ Parameters }} & \multicolumn{4}{|l|}{ Gender } \\
\hline & & \multirow{2}{*}{$\begin{array}{l}\text { Male } \\
\text { Mean } \pm \text { SD }\end{array}$} & \multirow[b]{2}{*}{ Number (\%) } & \multirow{2}{*}{$\begin{array}{l}\text { Female } \\
\text { Mean } \pm \text { SD }\end{array}$} & \multirow[b]{2}{*}{ Number (\%) } \\
\hline & & & & & \\
\hline Age (years) & & $55.2 \pm 7.7$ & & $59.4 \pm 8.4$ & \\
\hline \multicolumn{6}{|c|}{ Body Mass Index $\left(\mathrm{kg} / \mathrm{m}^{2}\right)$} \\
\hline \multirow[t]{2}{*}{ BMI Category } & Underweight & \multirow[t]{2}{*}{$31.09 \pm 6.82$} & 0 & \multirow{2}{*}{$28.88 \pm 5.7$} & 0 \\
\hline & Normal & & $8(16.7 \%)$ & & $6(35.3 \%)$ \\
\hline
\end{tabular}


Citation: Hasan A, Uzma N, Abdullah F, Hannan HA, Narasimhan C, et al. (2017) Is Obstructive Sleep Apnea more Prevalent than Central Sleep Apnea in Patients with Systolic Heart Failure? A Retrospective Study. J Clin Respir Dis Care 3: 126. doi:10.4172/2472-1247.1000126

Page 4 of 7

\begin{tabular}{|c|c|c|c|c|c|}
\hline & Overweight & & $16(33.3 \%)$ & & $2(11.8 \%)$ \\
\hline & Obese & & $21(43.8 \%)$ & & $9(52.9 \%)$ \\
\hline & Morbid obesity & & $3(6.3 \%)$ & & 0 \\
\hline \multirow[t]{3}{*}{ Heart failure category } & Mild & & $5(10.4 \%)$ & & $3(17.6 \%)$ \\
\hline & Moderate & & $27(56.3 \%)$ & & $12(70.6 \%)$ \\
\hline & Severe & & $16(33.3 \%)$ & & $2(11.8 \%)$ \\
\hline \multicolumn{6}{|c|}{ Apnea Hypopnea Index (Events/hour) } \\
\hline \multirow[t]{4}{*}{ AHI Category (Events/hour) } & Normal & \multirow{7}{*}{$33.2 \pm 17.7$} & 0 & \multirow{7}{*}{$26.9 \pm 17.1$} & 0 \\
\hline & Mild & & $11(22.9 \%)$ & & $4(23.5 \%)$ \\
\hline & Moderate & & $15(31.3 \%)$ & & $8(47 \%)$ \\
\hline & Severe & & $22(45.8 \%)$ & & $5(29.4 \%)$ \\
\hline \multirow[t]{4}{*}{ Sleep-disordered breathing } & Mixed & & 0 & & 0 \\
\hline & Central sleep apnea & & $2(4.2 \%)$ & & $1(5.9 \%)$ \\
\hline & Obstructive sleep apnea & & $46(95.8 \%)$ & & $16(94 \%)$ \\
\hline & & \multicolumn{4}{|l|}{ Mean \pm SD } \\
\hline \multicolumn{2}{|l|}{ Sleep Efficiency (\%) } & \multicolumn{2}{|l|}{$74.6 \pm 13.6$} & \multicolumn{2}{|l|}{$77.4 \pm 11.4$} \\
\hline \multicolumn{2}{|l|}{ Apneas (Events/hour) } & \multicolumn{2}{|l|}{$45 \pm 37$} & \multicolumn{2}{|l|}{$39 \pm 29$} \\
\hline \multicolumn{2}{|l|}{ Hypopneas (Events/hour) } & \multicolumn{2}{|l|}{$114 \pm 66$} & \multicolumn{2}{|l|}{$82 \pm 60$} \\
\hline \multicolumn{2}{|l|}{ Apnea REM (Events/night) } & \multicolumn{2}{|l|}{$2 \pm 5$} & \multicolumn{2}{|l|}{$1 \pm 2$} \\
\hline \multicolumn{2}{|l|}{ Apnea NREM (Events/night) } & \multicolumn{2}{|l|}{$13 \pm 12$} & \multicolumn{2}{|l|}{$8 \pm 11$} \\
\hline \multicolumn{2}{|l|}{ Hyponea REM (Events/night) } & \multicolumn{2}{|l|}{$5 \pm 9$} & \multicolumn{2}{|l|}{$3 \pm 6$} \\
\hline \multicolumn{2}{|l|}{ Hyponea NREM (Events/night) } & \multicolumn{2}{|l|}{$110 \pm 68$} & \multicolumn{2}{|l|}{$74 \pm 61$} \\
\hline \multicolumn{2}{|l|}{ Wake-after-sleep Onset (min) } & \multicolumn{2}{|l|}{$90.0 \pm 50.8$} & \multicolumn{2}{|l|}{$74.2 \pm 44.5$} \\
\hline \multicolumn{2}{|l|}{ Lowest $\mathrm{O}_{2}$ saturation (\%) } & \multicolumn{2}{|l|}{$78.8 \pm 11$} & \multicolumn{2}{|l|}{$78.5 \pm 7.7$} \\
\hline
\end{tabular}

Table 2: Gender specific demographic data. 


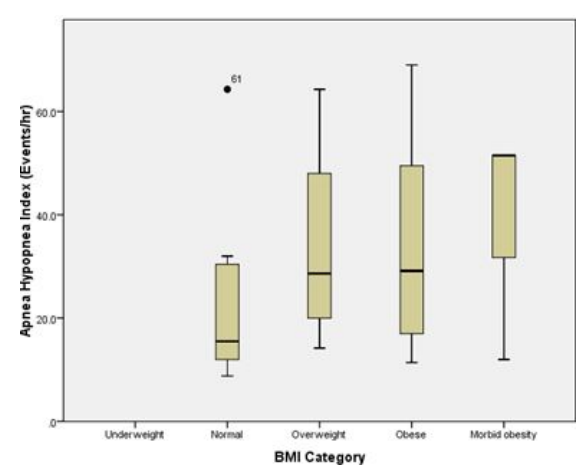

Figure 1: Changes in mean Apnea-Hypopnea Index in accordance with BMI.

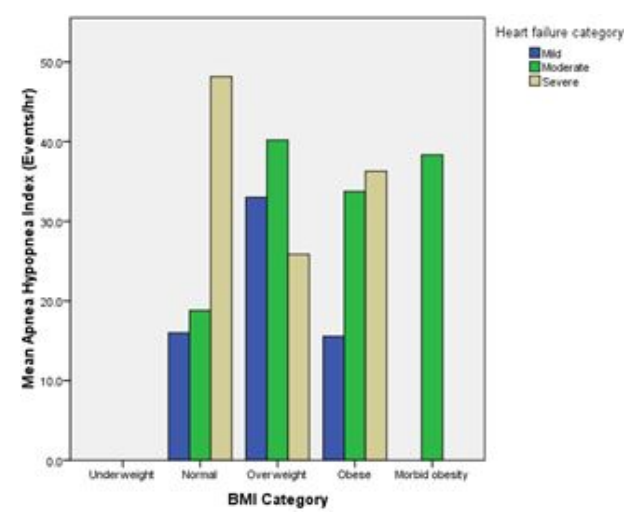

Figure 2: Analysis of severity of heart failure in accordance with $\mathrm{BMI}$ and $\mathrm{AHI}$

\section{Discussion}

Sleep-related breathing disorders are highly prevalent in patients with established cardiovascular disease [13]. It has relatively recently been recognized that obstructive and central sleep apnea are both common in heart failure, and may participate in its progression by exposing the heart to intermittent hypoxia, increased preload and afterload, sympathetic activation and vascular endothelial dysfunction. As well it has been acknowledged that effective treatment of sleep apnea in patients with heart failure may reverse these detrimental effects, while alleviating symptoms of sleep apnea. SDB in the context of heart failure in Indian patients has not been well characterized.

In general, the symptoms of CSA are witnessed apneas without significant snoring, insomnia and fatigue. Since CSA patients generally have relatively severe heart failure, symptoms such as orthopnea, paroxysmal nocturnal dyspnea are present as well [14]. On the other hand the defining symptom of OSA is loud snoring, which along with witnessed apneas, excessive daytime somnolence, fatigability and decreased cognition completes the constellation of the OSA syndrome [15].

The objectives of this study were to assess the characteristics of heart failure patients with regard to the prevalence of dominant type of sleep apnea whether OSA/CSA or Mixed SA. The impact of the severity of heart failure on the severity of sleep apnea was studied and the results were compared with those of similar studies available in the literature.

The mean $( \pm$ SD) age of the study population was $56 \pm 8$ years. The most dominant events in sleep were found to be the obstructive event in both males and females when compared to central and mixed events (Table 2). In other words, obstructive sleep apnea was by far the dominant sleep apnea. This finding contradicts the popular notion that central rather than obstructive sleep apnea is the dominant form of sleep apnea in heart failure, a finding that has been hitherto supported by a wealth of literature [16-18]. Thus, the present study challenges the previous paradigm that CSA is the most common sleep apnea in heart failure.

However these results were in accordance with previous studies carried out by who also showed OSA as the dominant sleep in heart failure patients [7,19-21].

Sin et al carried out study in 450 men and women with congestive heart failure at the Sleep Research Laboratory of the Toronto Rehabilitation Institute and the Departments of Medicine, The Toronto Hospital and Mount Sinai Hospital, University of Toronto, Toronto, Ontario, Canada to assess the risk factors for central and obstructive sleep apnea and found that OSA was the dominant sleep apnea.

Similarly Ferrier et al. carried out studies in 87 patients at WellSleep, Sleep Investigation Centre, Wellington School of Medicine, New Zealand in 55 male patients at sleep lab in Central London and in 218 patients at the Heart Failure Clinic of the Mount Sinai Hospital and all found that sleep disordered breathing was common in heart failure patients, with OSA being the dominant form [19-20]. Thus, the growing literature reflects that the dominance of OSA in heart failure is not restricted to one part of the globe. The above studies were carried out exclusively in Caucasian dominant populations. This study addresses for the first time the sleep apnea profile in Indian patients with heart failure.

In this study, it was found that the association of OSA in heart failure was more common in men than women who again are consistent with the study carried out by the following authors: Sin et al. had carried out studies in 450 patients of which 382 were males (85\%), Ferrier K et al. had 87 patients of which $77 \%$ were males. Yumino D et al. had 218 patients in which predictors of OSA and CSA were males.

In 2006, a population-based survey from North India had estimated the overall prevalence of OSA in the screened population was $13.7 \%$ and that of OSAS was $3.57 \%$. (males $19.7 \%$ and females $2.1 \%$ respectively in the general population [22]. Recently, prevalence and risk factors of OSAS in different socio- economic classes in an urban Indian population have been reported from South Delhi. The authors observed a prevalence of OSA to be $9.3 \%$ and OSAS to be $2.8 \%$. The prevalence of OSA and OSAS in males was $13.4 \%$ and $4 \%$ respectively whereas in females, these were $5.6 \%$ and $1.5 \%$ respectively. Thus, the prevalence of OSA in the Indian population is three-fold higher in men as compared to women [23].

The incidence of OSA increases with age; however age is not an independent risk factor for the OSA. The mean $( \pm \mathrm{SD})$ age of the study population was $56 \pm 8$ years. The mean age of males was $55.2 \mathrm{yrs}$ and females were 594 .

In this study about $23 \%$ of patients had mild AHI, $35.4 \%$ of patients had moderate AHI and $41.5 \%$ of patients had severe AHI, reflecting the strong association of AHI with the severity of incident heart failure (Table 1 and Figure 2). 
Page 6 of 7

Patients that belong to obesity class 1 (the less obese patients) constitute the majority of heart failure patients. Thus the prevalence of relatively severe obesity in heart failure patients in this study was not very high, most patients being only mildly obese. Most of the patients with moderate and severe AHI abnormality fell into obesity Class-1. Heart failure patients frequently lose muscle weight due to low cardiac output and a consequent reduction in physical activity a condition described as cardiac cachexia as well as of course voluntarily. Of note, low body weight has recently been correlated with an increased mortality in heart failure [24,25].

When the sleep efficiency was compared to EF, it was found paradoxically that patients with relatively higher EF had worse sleep efficiency compared to those patients with lower EF. When the sleep efficiency was contrasted with the severity of AHI, it was found that the severity of AHI correlated with poor sleep efficiency.

Between patients with EF between $35-45 \%$ and $45-55 \%$, patients with relatively higher $\mathrm{EF}$ had higher $\mathrm{AHI}$, thus demonstrating an inverse correlation of AHI with LV ejection fraction. However, for more severe heart failure $(\mathrm{EF}<35 \%)$, this relationship could not be further explored owing to the paucity of patients in this group. The possible explanation for this apparent aberration seems to be that the cohort with severe heart failure was comprised of relatively underweight patients as compared the cohort with less severe heart failure. Although being underweight is known to be associated with adverse outcomes in HF per se it is also recognized that low body weight can be protective against sleep apnea of the obstructive type [26]. Thus, it is possible that the patients with lower EF have had less severe OSA on account of the 'protection' afforded by a lower BMI. The significance of this finding is that weight loss in heart failure patients could offer a significant protective benefit against the development of OSA in precisely those patients who are most at risk for heart failure mortality on account of being underweight. One study by Malone et al. did note that the usual symptoms of OSA do not occur with the usual frequency in the presence of heart failure [27].

This explanation does not seem to be all encompassing. Some epidemiological studies have in fact suggested that uncharacterized protective mechanisms could be operative in heart failure patients [28]. The enigma is further compounded by the observation that Gottleib et al. did not find any association of sleep disordered breathing and cardiovascular morbidity while noted a paradoxically increased survival of elderly patients with relatively mild OSA [29,30].

A few other points merit attention. Firstly, all the patients who underwent PSG for a possible diagnosis of SDB had sleep apnea diagnosed at the end of the study. This was for the reason that only those patients with a fairly strong pretest probability of SDB (based on EDS and fatigability) were considered for polysomnography although of course EDS and fatigability, could equally suggest heart failure. Secondly, the screening evaluation did not specifically look for a history of snoring: it relied rather on the suspicion of a sleep apnea based on a preliminary screening history of EDS and fatigability which was considered by the treating cardiologist to be out of proportion to the heart failure alone. In other words a potential observer bias which could have led to an inclusion of disproportionately more OSA patients if a screening history of snoring or snorting during sleep were included was avoided. Thirdly, since the results of this study showed that in patients with HF, a high pretest clinical probability of OSA invariably translates into a diagnosis of OSA, a history of excessive daytime somnolence and fatigue as well as of snoring becomes of critical importance in patients with HF, though as discussed, the same symptoms might possibly occur on account of the HF alone. Finally, the appearance of significant OSA in patients with lesser severities of HF (especially with relatively overweight patients) means that such PSG-testing should be considered even in patients with less severe HF.

\section{Conclusion}

By far the most dominant form of SDB in HF in Indian patients seems to be OSA. More men than women appear affected. The severity of HF significantly impacts sleep efficiency. The most severe categories of heart failure seem to protect against severe OSA and severe desaturations.

Finally, the presence of HF can mask the presence of OSA: a high pretest clinical probability of SDB almost invariably translates into a diagnosis of OSA, and so a history of daytime somnolence and fatigue as well as snoring should always be taken in patients with less severe HF especially if they are overweight.

\section{Acknowledgments}

The authors thank all the participants who have enrolled in this study.

\section{Funding}

No funding was received for this research.

\section{Conflict of Interest}

All authors certify that they have no affiliations with or involvement in any organization or entity with any financial interest or nonfinancial in the subject matter or materials discussed in this manuscript.

\section{Ethical Approval}

All procedures performed in studies involving human participants were in accordance with the ethical standards of the institutional and/or national research committee and with the 1964 Helsinki declaration and its later amendments or comparable ethical standards.

\section{Informed Consent}

Informed consent was obtained from all individual participants included in the study.

\section{References}

1. Roger VL (2013) Epidemiology of heart failure. Circ Res 113: 646-659.

2. Mosterd A, Hoes AW (2007) Clinical epidemiology of heart failure. Heart 93: 1137-1146.

3. Daly PA, Sole MJ (1990) Myocardial catecholamines and the pathophysiology of heart failure. Circulation. 82: I35-I43.

4. Floras JS (1993) Clinical aspects of sympathetic activation and parasympathetic withdrawal in heart failure. J Am Coll Cardiol 22: 72A-84A.

5. Callop N, Cassel DK (2012) Snoring and sleep disordered breathing. Sleep Med: 349-355.

6. Young T, Peppard PE, Gottlieb DJ (2002) Epidemiology of obstructive sleep apnea: A population health perspective. Am J Respir Crit Care Med 165: 1217-1239. 
Citation: Hasan A, Uzma N, Abdullah F, Hannan HA, Narasimhan C, et al. (2017) Is Obstructive Sleep Apnea more Prevalent than Central Sleep Apnea in Patients with Systolic Heart Failure? A Retrospective Study. J Clin Respir Dis Care 3: 126. doi:10.4172/2472-1247.1000126

Page 7 of 7

7. Sin DD, Fitzgerald F, Parker JD, Newton G, Floras JS, et al. (1999) Risk factors for central and obstructive sleep apnea in 450 men and women with congestive heart failure. Am J Respir Crit Care Med 160: 1101-1106.

8. Dempsey JA, Veasey SC, Morgan BJ, O’Donnell CP (2010) Pathophysiology of sleep apnea. Physiol Rev 90: 47-112.

9. Caples SM, Wolk R, Somers VK (2005) Influence of cardiac function and failure on sleep-disordered breathing: Evidence for a causative role. J Appl Physiol 99: 2433-2439.

10. Naughton MT, Andreas S (2010) Sleep apnoea in chronic heart failure. Eur Respir Mon 50: 396-420.

11. Meoli AL, Casey KR, Clark RW, Coleman JA Jr, Fayle RW, et al. (2001) Hypopnea in sleep-disordered breathing in adults. Sleep 24: 469-470.

12. Flegal KM, Carroll MD, Ogden CL, Johnson CL (2002) Prevalence and trends in obesity among US adults, 1999-2000. JAMA 288: 1723-1727.

13. Budhiraja R, Budhiraja P, Quan SF (2010) Sleep disordered breathing and cardiovascular disorders. Respir Care 55: 1322-1332.

14. Eckert DJ, Jordan AS, Merchia P, Malhotra A (2007) Central sleep apnea: Pathophysiology and treatment. Chest: 131: 595-607.

15. Mbata GC, Chukwuka JC (2012) Obstructive sleep apnea hypopnea syndrome. Ann Med Health Sci Res 2: 74-77.

16. Javaheri S, Parker TJ, Liming JD, Corbett WS (1998) Sleep apnea in 81 ambulatory male patients with stable heart failure: Types and their prevalences, consequences and presentations. Circulation. 97: 2154-2159.

17. Tremel F, Pepin JL, Veale D, Wuyam B, Siche JP (1999) High prevalence and persistence of sleep apnea in patients referred for acute left ventricular failure and medically treated over 2 months. Eur Heart J 20: 1201-1209.

18. Lanfranchi PA, Somers VK, Braghiroli A, Corra U, Eleuteri E, et al. (2003) Central sleep apnea in left ventricular dysfunction, prevalence and implications for arrhythmic risk. Circulation 107: 727-732.

19. Ferrier K, Campbell A, Yee B, Richards M, O'Meeghan T, et al. (2005) Sleep-disordered breathing occurs frequently in stable outpatients with congestive heart failure. Chest 128: 2116-2122.

20. Vazir A, Hastings PC, Dayer M, McIntyre HF, Henein MY, et al. (2007) A high prevalence of sleep disordered breathing in men with mild symptomatic chronic heart failure due to left ventricular systolic dysfunction. Eur J Heart Fail 9: 243-250.

21. Yumino D, Wang H, Floras JS, Newton GE, Mak S, et al. (2009) Prevalence and physiological predictors of sleep apnea in patients with heart failure and systolic dysfunction. J Card Fail 15: 279-285.

22. Sharma SK, Kumpawat S, Banga A, Goel A (2006) Prevalence and risk factors of obstructive sleep apnoea syndrome in a population of Delhi, India. Chest 130: 149-156.

23. Reddy EV, Kadhivaran T, Mishra HK, Sreenivas V, Handa KK, et al. (2009) Prevalence and risk factors of obstructive sleep apnoea among middle-aged urban Indians: A community based study. Sleep Med 10: 913-918.

24. O’Connor CM, Anderson SA, Meese RB (1997) Clinical determinants of outcome in advanced heart failure: Insights from the PRAISE trial. J Am Coll Cardiol 129: 246A.

25. Anker SD, Ponikowski P, Varney S, Chua TP, Clark AL, et al. (1997) Wasting as independent risk factor for mortality in chronic heart failure. Lancet 349: 1050-1053.

26. Pocock SJ, McMurray JJ, Dobson J, Yusuf S, Granger CB, et al. (2008) Weight loss and mortality risk in patients with chronic heart failure in the candesartan in heart failure: assessment of reduction in mortality and morbidity (CHARM) programme. Eur Heart J 29: 2641-2650.

27. Rutherford R, Malone S, Liu PP, Bradley TD, Holloway R (1991) Obstructive sleep apnoea in patients with dilated cardiomyopathy: Effects of continuous positive airway pressure. Lancet 338: 1480-1484.

28. Lavie L (2015) Oxidative stress in obstructive sleep apnea and intermittent hypoxia-revisited-the bad ugly and good: Implications to the heart and brain. Sleep Med Rev 20: 27-45.

29. Gottlieb DJ, Yenokyan G, Newman AB, O'Connor GT, Punjabi NM, et al. (2010) Prospective study of obstructive sleep apnea and incident coronary heart disease and heart failure. Circulation 122: 352-360.

30. Lavie P, Lavie L (2009) Unexpected survival advantage in elderly patient with moderate sleep apnea. J Sleep Res 18: 397-403. 